\title{
вмј Global Health Sickle cell disease in India: a scoping review from a health systems perspective to identify an agenda for research and action
}

To cite: Raman V, Seshadri T, Joice SV, et al. Sickle cell disease in India: a scoping review from a health systems perspective to identify an agenda for research and action. BMJ Global Health 2021;6:e004322. doi:10.1136/ bmjgh-2020-004322

Handling editor Seye Abimbola

- Additional material is published online only. To view, please visit the journal online (http://dx.doi.org/10.1136/ bmjgh-2020-004322).

VR and PNS contributed equally.

Received 11 November 2020 Revised 7 January 2021 Accepted 26 January 2021

Check for updates

(c) Author(s) (or their employer(s)) 2021. Re-use permitted under CC BY. Published by BMJ.

${ }^{1}$ Health equity cluster, Institute of Public Health, Bangalore, India

${ }^{2}$ Tribal Health Resource Centre, Vivekananda Tribal Welfare Center, BR Hills, Karnataka, India ${ }^{3}$ Department of Biochemistry, Malabar Medical College and Research Centre, Modakkallur, India

Correspondence to Dr Prashanth N Srinivas; prashanthns@iphindia.org

\section{ABSTRACT}

Introduction Sickle cell disease (SCD) disproportionately impacts Adivasi (tribal) communities in India. Current research has focused on epidemiological and biomedical aspects but there has been scarce research on social determinants and health systems aspects. Given its fragmented distribution, resources and programmes have emerged in west and central India. This scoping review seeks to identify geographical and evidence gaps for action on SCD from a health systems lens.

Methods We followed a scoping review protocol, using Google Scholar and PubMed for published literature. Keywords used included sickle cell anaemia/disease, health systems, tribal and India. We used Google search for grey literature. We compiled a list of 55 records (of which 35 were retained), with about half pertaining directly to India and others relevant to similar settings. Results were organised and analysed using the WHO health systems framework to identify geographical and evidence gaps.

Results We found substantial literature on biomedical and clinical aspects of SCD but little on the design and implementation of programmes in community and Adivasispecific contexts as well as on social determinants of SCD. There were regional gaps in knowledge in southern and northeast India. Wherever community-based programmes exist, they have originated in civil society initiatives and relatively limited state-led primary healthcare-based efforts pointing to weak agenda setting.

Conclusion Both research and action on SCD especially among tribal populations need immediate attention. While geospatial epidemiology has been well understood, gaps remain in context-specific knowledge for action in several parts, as well as evidence gaps across several health system building blocks, including governance and financing of care. Despite publication of a draft policy, delayed adoption and lapses in implementation have limited the response largely to local communities and nongovernmental organisations.

\section{INTRODUCTION}

Being a neglected health problem, the overall research on sickle cell disease (SCD) has also been scarce in India. ${ }^{1-3}$ Furthermore, research

\section{Key questions}

What is already known?

- Certain populations (like tribal people) and regions in India are disproportionately affected by sickle cel disease (SCD) but significant knowledge and action gaps persist in developing comprehensive programmes for care for SCD.

- The literature available on SCD focuses on epidemiological or biomedical aspects, fragmented across disciplines and regions with little attention to the aspects of social determinants or health systems.

What are the new findings?

- Significant gaps in comprehensiveness of research exist particularly concerning design, implementation or systematic appraisal of quality of care for patients with SCD; this in addition to lack of long-term studies critically limits the availability of evidence of healthcare outcomes in SCD.

- Studies focusing on individual, community and health system blocks were absent; these studies were lacking in terms of coverage from various geographical regions where SCD is reported.

- Most research drew on health services or innovations provided in NGO settings with few studies analysing government health services' response to SCD at regional/national level.

What do the new findings imply?

- Further studies on SCD need to urgently focus on the gaps in geographical coverage of evidence highlighted as well as in comprehensiveness of evidence across individual, population, services and systems levels.

- Research on SCD in India needs to engage with the axes of social inequalities including socioeconomic position, gender, geography and other social vulnerabilities (currently absent) to address the health inequities in SCD.

on SCD remains fragmented across disciplinary areas, largely from the biomedical disciplines (especially haematology, pathology 
and genetics), with limited application of a broad, interdependent and dynamic health systems perspective. The WHO defines a health system to include 'all organisations, people and actions whose primary intent is to promote, restore or maintain health' with the goal of 'improving health and health equity in ways that are responsive, financially fair, and make the best or most efficient, use of resources'. ${ }^{45}$ There is currently no national or state-led programmes or frameworks outlining a health systems approach towards SCD, although a draft policy notified by the Ministry of Health and Family Welfare exists. ${ }^{6}$ However, in remote tribal population settings, there have been exceptional non-governmental organisation (NGO)-led efforts at responding to the problem with limited coordination with public health services.

Since the early 20 th century, various haemoglobinopathies have been described. The prevalence of sickle-cell haemoglobin, the result of an amino acid substitution due to a point mutation in the gene coding for one of the constituent proteins of haemoglobin, was first examined in India by Australian and British pathologists. Crosssectional prevalence surveys among various communities in India in the 1950s and 1960s documented prevalence particularly among tribal populations with high variation within and across tribal communities, ${ }^{7}$ ranging from as low as $1 \%$ to $40 \%-55 \%{ }^{8}$ Since then, its prevalence is described as being high among particular tribal communities with regionally higher prevalence in several non-tribal yet socially disadvantaged population groups such as other backward classes and scheduled castes. ${ }^{8}$ Recent reviews of SCD are comprehensive ${ }^{9}$ and have attempted to summarise its spatial and population prevalence largely from sporadic cross-sectional surveys. However, the disease's distribution in socially disadvantaged population groups who already face difficulties of access to health services and inequities necessitates a health systems approach that goes beyond characterising prevalence and clinical features and attempts to identify actionable gaps in our contextual understanding of the disease. The health systems approach is based on a view that health status and healthcare are determined not only by access to clinical and primary healthcare services, but also through wider social determinants of health and through a complex and dynamic interaction across various functions (building blocks) of an ideal health system that requires a transdisciplinary approach towards building strong health systems. In keeping with making research more people centred, a health systems approach foregrounds local context, actors and 'human agency attributes and values, and is acutely attentive to the local policy and community context'. ${ }^{10}$ Hence, we propose to examine the research available from a health policy and systems research lens to advance an agenda towards action on SCD.

Various frameworks exist for analysing health systems including the six building blocks framework by the WHO: these are service delivery, health workforce, health information systems, access to essential medicines, financing, leadership/governance. ${ }^{4}$ One of the key principles of health systems thinking, however, is the dynamic and interacting nature of these building blocks and the context-specific nature of their interactions. ${ }^{11}$ Furthermore, the social construction and the people-oriented nature of health systems have been importantly highlighted by various researchers. ${ }^{10} 1213$ The intersection of neglected tropical disease (NTD) control programmes and health services and systems has also been well documented. ${ }^{14}$ Successful NTD control programmes require effective health systems. Wherever specific NTD control programmes can be integrated with health systems, they can serve to both use existing structures and resources and strengthen new functions that can have system-wide positive effects for other disease control programmes as well. ${ }^{15}$ The biomedical framing of SCD and the neglect of wider social inequalities and determinants of health in Africa have been highlighted, but a similar assessment is lacking for the diverse social, geographical and cultural contexts in India. ${ }^{16}$

SCD disproportionately impacts vulnerable tribal communities in India. Despite many studies documenting epidemiological burden among tribal populations ${ }^{9}$ and the feasibility of screening methods in low-resource settings ${ }^{17}$ several knowledge and action gaps remain in developing comprehensive programmes to provide care for affected communities. SCD has been designated as an NTD, largely because of its burden on the most disadvantaged populations in sub-Saharan Africa and tribal groups in India. ${ }^{1}$ India has the second highest SCD burden in the world ${ }^{18}$ and within India it impacts socially, politically and economically marginalised groups, especially scheduled tribes. ${ }^{9}$ The higher prevalence of SCD among forest-dwelling tribal communities necessitates an urgent need for action from an equity perspective given other drivers of social inequalities among SCD-affected tribal communities.

In this paper, we aim to apply a health systems lens to assess existing research on SCD and identify key gaps in our knowledge of SCD in India, with a particular focus on the need for research and action on SCD among tribal population of India, in order to guide health systems strengthening initiatives for SCD. By bringing a health systems lens onto SCD literature, we hope to steer the SCD research agenda towards evidence that can guide context-specific action on SCD especially among tribal populations in low/limited-resource settings.

\section{METHODS}

\section{Review protocol}

A scoping review protocol was developed (online supplemental file 1). The protocol followed the six-step methodological approach to scoping reviews described by Arksey and O'Malley. ${ }^{19}$ Starting with the research question, the relevant studies were identified through database searches. The search results were scanned based on criteria described below. The information from the 
papers retained was then mapped onto a framework (equivalence to charting the data) and summarised. The review team included researchers with expertise in biochemistry, community health, and health policy and systems research.

\section{Review question and scope}

The review sought to particularly focus on tribal population. While various labels are applied for tribal population in India, we have chosen the label tribal population to refer to forest-associated communities that are included in statutory lists (the Scheduled Tribe). For a brief overview on the implications of the different labels used in literature to refer to tribal communities, see Srinivas $e t$ $a l .{ }^{20}$ Literature was screened for relevance to SCD based in India or low-resource, tribal population settings as well as literature that assesses one or more building blocks of health systems. Literature was excluded if it pertained to mainly high-income settings, was exclusively epidemiological inquiry without health system components or did not have a substantial focus on health systems in low resource or community settings. Some records from high-income settings were included in our synthesis if they focused on a vulnerable group. While assessing fit of literature, we focused particularly on tribal communities in south India due to relatively limited research and policy attention to south Indian tribal populations given their relatively smaller numbers in south Indian states, when compared with central and northeast Indian regions. ${ }^{21-23}$

\section{Search strategy}

We identified peer-reviewed research papers through searches in PubMed and Google Scholar and supplemented these with technical reports and other grey literature (not peer reviewed) through Google web search. The searches were performed in January and February 2020 with no limit on the dates of publications. Search terms included Boolean queries comprised of the following terms: sickle cell anaemia/disease, tribal community/ population/people, indigenous communities, ST/ scheduled tribe, vulnerable/marginalized population, Adivasi, health system, treatment, prevention, Karnataka, south India and India (see online supplemental table 1 supporting information for search strategy).

\section{Relevance screening and inclusion criteria}

Articles were screened by title to ensure relevance to SCD. The abstracts were then examined to assess relevance for health systems aspects. A total of 131 articles with SCD and/or health systems in their title were identified. Of these, a final list of 35 full-text articles were used in the review (excluded 85 studies that were purely reporting clinical aspects of SCD and 55 duplicates). Each step was performed by the first author and verified by coauthors. The 35 full-text articles were read by at least two authors. A summary of the search term strategy, number of results and screening process is shown below in figure 1. Additional details regarding search terms are available in online supplemental table 1 supporting document. The list of records is available in online supplemental table 2.

\section{Conceptual framework}

In order to organise the evidence identified and identify gaps, there is a need to conceptualise a framework that maps out the elements on which evidence is needed, their relationships and levels at which they operate (individual, populations/community and the wider system). In line with the overall approach in health policy and systems research of grounding research and action agenda with people at the centre, ${ }^{12}$ we iteratively identified themes emerging from the review and from existing health systems frameworks ${ }^{524}$ for the purposes of assessing research and action on SCD in Indian settings (see figure 2). To assess comprehensiveness of evidence available for each level and component of the framework, we identified key parameters (online supplemental table 2). We foresee the conceptual framework and these parameters to be an aspirational or ideal set of conditions that helps identify knowledge and evidence gaps to guide the research agenda on SCD in the region. Comprehensiveness was assessed in terms of the parameters defined for each component in online supplemental table 2. For example, to assess comprehensiveness of evidence with respect to life course, we assessed whether the evidence addresses manifestations and illness experience across life course (childhood, neonatal, adult) as well as special categories (pregnant women, elderly). Coverage was measured by assessing geographical coverage across regions.

\section{RESULTS}

\section{Summary of the literature}

Fifty-three peer-reviewed papers along with two of grey literature were retained. Most records were primary literature $(n=26)$, with one-third of the records being secondary literature. Most articles $(n=33)$ were from low/middle-income countries (LMICs), with 25 articles from India. Twelve articles were from the USA and 19 overall were from higher income countries. Most primary authors were medical doctors $(\mathrm{n}=29)$ and from LMICs $(n=33)$. Most studies were funded internally by participating organisations/universities. Very few studies were funded by foreign sources $(n=7)$. Governments were the most common funders, whether through grant funding or institutions themselves. Many studies pertained to higher level planning and policy on sickle cell $(\mathrm{n}=19)$ and over a dozen detailed interventions in tertiary hospital settings $(\mathrm{n}=16)$. Nine studies described community settings. For full details, see online supplemental table 2. Given the importance of screening to detect cases of SCD, service delivery was the most common building block addressed. The second most common building block was access to essential medicines, highlighting the importance of hydroxyurea treatment for those with the sickle phenotype. 


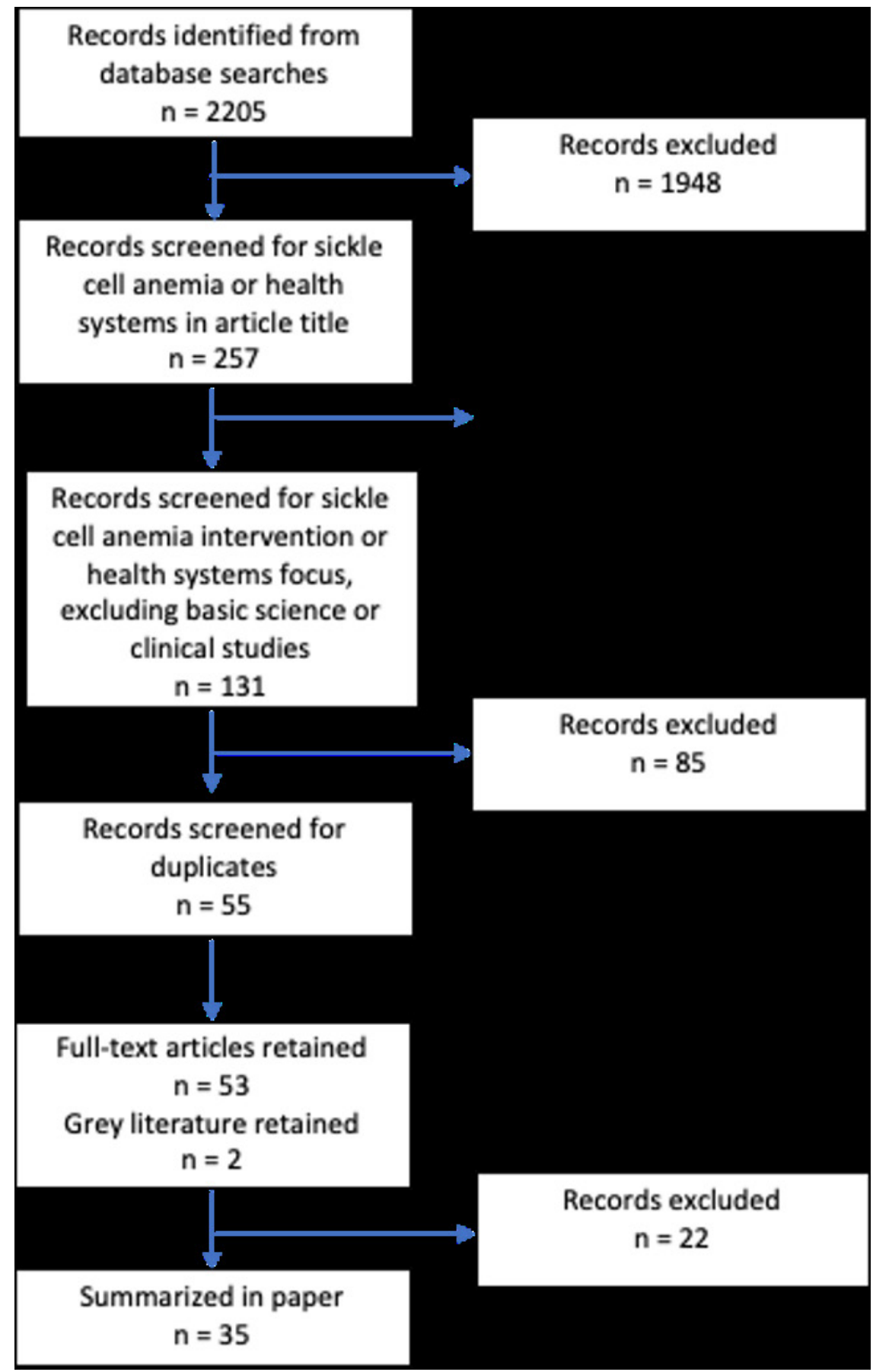

Figure 1 Flow chart on article screening and selection process.

\section{Conceptualising a health systems framework for guiding} action on sickle cell anaemia

A health systems response to SCD needs to be organised at multiple levels-individuals, population/community, health system-with associated attributes identified at each level. At the individual level, there is a need to understand SCD effects throughout the life course (age group) and its differential impacts based on various genetic and social attributes (gender, other social identities, including caste and comorbidities and vulnerabilities). At the population/community level, the need is to focus on population health parameters related to epidemiology, access to care and coverage of services/ programmes for population screening. At the health systems level, there is a need for identifying evidence related to health services (including aspects related to healthcare delivery such as diagnostics, treatment and clinical care, along with the need for evidence on quality of care provided and healthcare outcomes). At the interface of individuals and health systems too, there is a need for good quality evidence on healthcare-seeking behaviour, health promotion and rehabilitative services to affected individuals. At the health system level, there is a need for evidence on financing, information systems, 


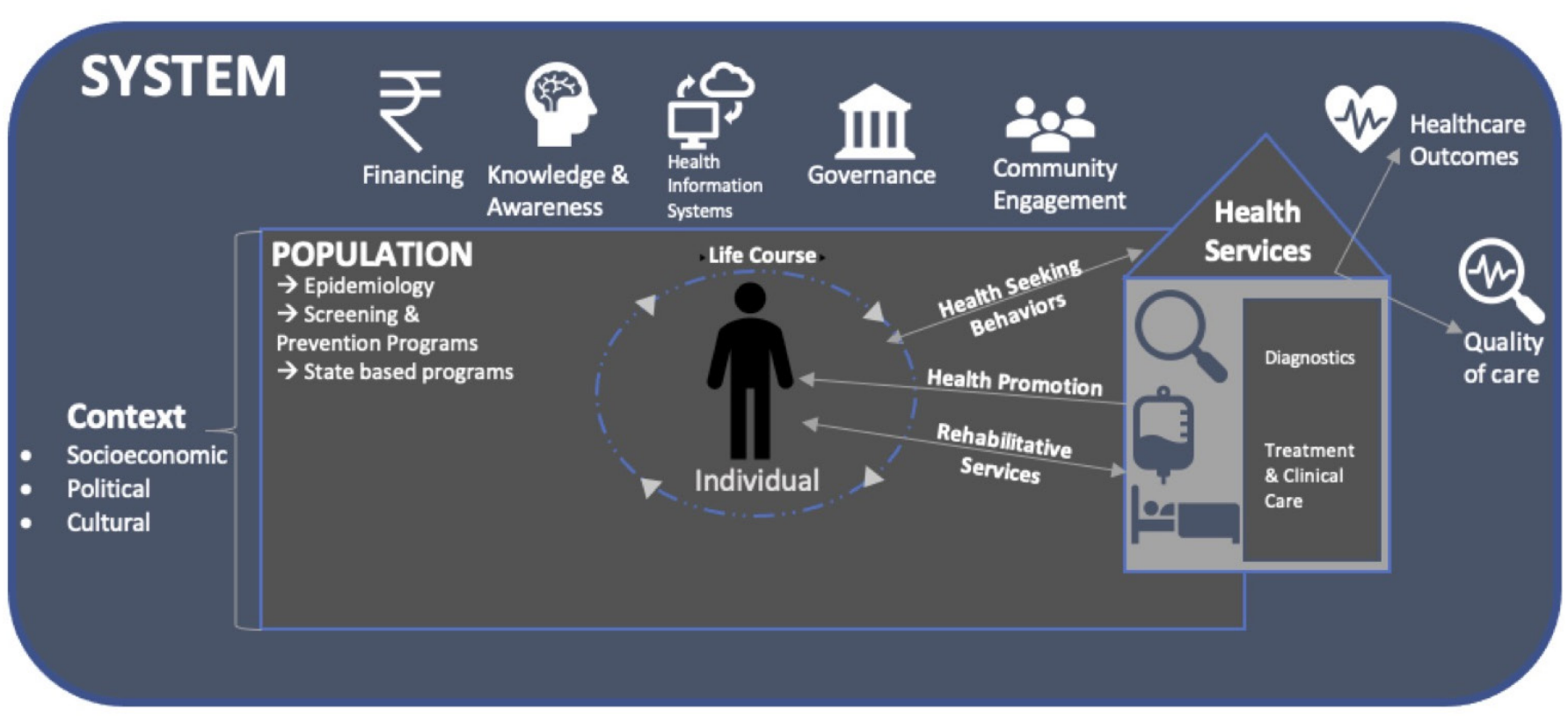

Figure 2 Diagram of conceptual framework for SCD health systems. SCD, sickle cell disease.

governance and system-level knowledge/awareness of SCD and its prioritisation. Finally, the importance of various socioeconomic, political and cultural factors influences outcomes at these levels with respect to SCD ought to be understood.

\section{Synthesis of evidence across health system components}

At the individual level, evidence specific to various life stages and health-seeking behaviour was considered. While both comprehensiveness and coverage were good, there is a lack of data from long-term studies addressing specific life stages which are more vulnerable (early infancy and childhood pregnancy). Only two studies examined health-seeking behaviour. ${ }^{25} 26$ Evidence in favour of community-based approaches is available from one specific setting where the involvement of existing trustful relationships between an NGO and the community were crucial in demonstrating effectiveness. ${ }^{26}$

At the population level, epidemiological and population health intervention-related evidence was examined. A recent and as yet, most comprehensive, geospatial analysis is available based on data from 18 states with the majority of the coverage from four states (Gujarat, Maharashtra, Odisha and Chhattisgarh). In terms of population health interventions that are adapted to particular settings, only two studies were found, one of an integrated health network with home visits for education and screening linked to care at a primary care clinic ${ }^{26}$ and another based on volunteer-led screening at village level. $^{27}$

At the health services level, we examined evidence on diagnosis, treatment, rehabilitative services, quality of care and treatment outcomes. This level was the most well studied although studies on rehabilitative services (especially home and community-based approaches) are absent. Lack of long-term studies also limits the availability of fine-scale data on quality of life and healthcare outcomes. The three programmes that are evaluated demonstrate positive outcomes in terms of utilisation and feasibility of community-based interventions for SCD. ${ }^{26} 27$

At the health system level, we examined evidence on financing, information systems, knowledge/awareness, governance and community engagement. Studies on financing and costing of SCD programmes, while scarce, demonstrate the costs of not implementing interventions in terms of the overall National Health Budget. ${ }^{28}$ The cost of blood requirements alone if haemoglobinopathy prevention programmes are not implemented would grow to $19 \%$ of the National Health Budget. ${ }^{28}$ In terms of health information systems, the lack of longterm data and registries or limited availability and integration of medical records has been studied with one study focusing on the potential for implementing electronic medical records systems and its implications on SCD. ${ }^{29}$ The knowledge and awareness components were addressed by studies that identified the role for parental education, role of a counsellor and community health worker in improving SCD care in hospital and community settings. ${ }^{25} 263031$ There are no studies that specifically address health systems governance at any level (ranging from local and districts to national), although gaps in governance with respect to ensuring access to SCD medicines have been examined in one study. ${ }^{31}$ There is limited diversity in studying community engagement for SCD with only two studies that examined this. ${ }^{2632}$

The socioeconomic, political and cultural context of SCD can be studied at multiple levels ranging from individual and households/neighbourhood to policy levels. Socioeconomic context was represented in the epidemiological terms. Only one study examined the political aspects in terms of community ownership at the 
micro-level. Critical analysis of the macro-level drivers including policies, wider social and political determinants, axes of social inequities including caste, gender, socioeconomic position and other vulnerabilities and how they affect people with SCD was lacking. Only one study examined the role of traditional health systems among one of the indigenous communities in southern Karnataka $^{33}$ despite widespread dependence on traditional medicines among many indigenous and rural communities. ${ }^{33} 34$

\section{DISCUSSION}

Considering the diversity of regional and social contexts from which SCD is reported, there is a need for the future research agenda to specifically address gaps in comprehensiveness of the evidence as well as its sociogeographical coverage. We organised these results in table 1 to illustrate these gaps alongside specific references.

\section{Gaps in comprehensiveness}

There were no studies pertaining to design, implementation or effectiveness of rehabilitative services for sickle cell anaemia or systematic appraisal of quality of care for patients with SCD. This is a critical gap that has implications for health systems response to SCD. Even globally, evidence on quality of care and outcomes of SCD is limited to high-income settings where the focus has been on establishing standards of care for adults and children. ${ }^{356}$ The lack of long-term studies (such as registries) also limits availability of evidence on healthcare outcomes. ${ }^{3}$ Due to lack of routine data on SCD from government or other health services and the lack of cohort or longitudinal studies involving tribal communities, there is insufficient evidence available related to the life course in Indian settings.

At the systems level, the bias towards studying individuals/communities as opposed to studies focusing on aspects of health policy and systems (governance, policies and financing of care) was conspicuous by their absence. Financing of SCD care in Indian settings is poorly analysed despite increased episodes of hospital admissions, emergency department usage and outpatient visits among patients with SCD being reported from other settings. In a health system with important gaps in achieving universal health coverage, this can impose an unfair burden on poor households further aggravating their socioeconomic hardships. The additional financial and infrastructural costs of caring for SCD in specific geographies need to inform state and regional policy and practice guidelines in order to ensure adequate health systems response, given increased costs of care on primary health centres and local governments with high proportion of patients with SCD.

\section{Gaps in coverage}

Studies on rehabilitative care, quality of care and cultural aspects of SCD were completely absent, whereas studies on governance, financing and community engagement were poor in terms of coverage of different geographical regions from where SCD is reported. Rehabilitative services are one of the four components of primary healthcare but are neglected. Given the varied physical (painful SCD crises among young adults, easy fatigability especially among disadvantaged populations that depend on daily wage physical labour) and psychosocial manifestations of SCD, having access to counselling and social services that can protect patients from socioeconomic consequences is important especially among tribal and disadvantaged community settings. While studies that report on various aspects of the individual life course are good in terms of geographical coverage, population-level studies are mainly drawn from cross-sectional surveys, with limited analysis of routine hospital/healthcare data.

\section{SCD and tribal populations}

There is an overall scarcity of research on health of tribal populations in India, ${ }^{22}$ and the scarcity of evidence for action on SCD on tribal populations is hence not surprising. Given the heterogeneity of the geographical and social contexts of tribal communities, the spatial epidemiological pattern ${ }^{18}$ as well as patterns of health inequalities among tribal populations ${ }^{20} 37$ necessitates a more regional and decentralised research and action agenda for tribal populations. Most studies on SCD tend to draw on health services or innovations provided in civil society/NGO settings (see below) and there were few studies that evaluate or analyse overall government health services or health systems response to SCD at regional/ state or national level. The overall agenda setting for research and action on SCD too in terms of design and implementation of interventions is limited to NGO-led initiatives as opposed to state-led ones. ${ }^{31}$ There is scarce literature on the cultural context of SCD in the Adivasi/ non-Adivasi landscape and few details of traditional treatments for SCD, except for a single commentary on traditional medicinal preparations used by the Soliga people in southern Karnataka. ${ }^{33}$ In Italy, Colombatti ${ }^{38}$ describes how comprehensive SCD care can be delivered to vulnerable groups and obtain high adherence if linguistic, cultural and social issues are addressed, ${ }^{38}$ echoing the findings of Nimgaonkar and Desai in India. ${ }^{26}$ SCD in tribal populations has to be seen in relation to the unfairly higher burden of malnutrition, tuberculosis and malaria, increasing burden of non-communicable diseases and the wider social determinants of their health stemming from poverty, exclusion and historical injustice ${ }^{39}$ which current literature does not appear to reflect given stronger anchoring within biomedical and epidemiological starting points. Indeed, as pointed out by the Indian government's expert committee on tribal health, restructuring of health services and systems among tribal populations to allow for greater participation and voice to local communities is vital, and research types that allow documentation of good practices from such initiatives such as implementation research and participatory 


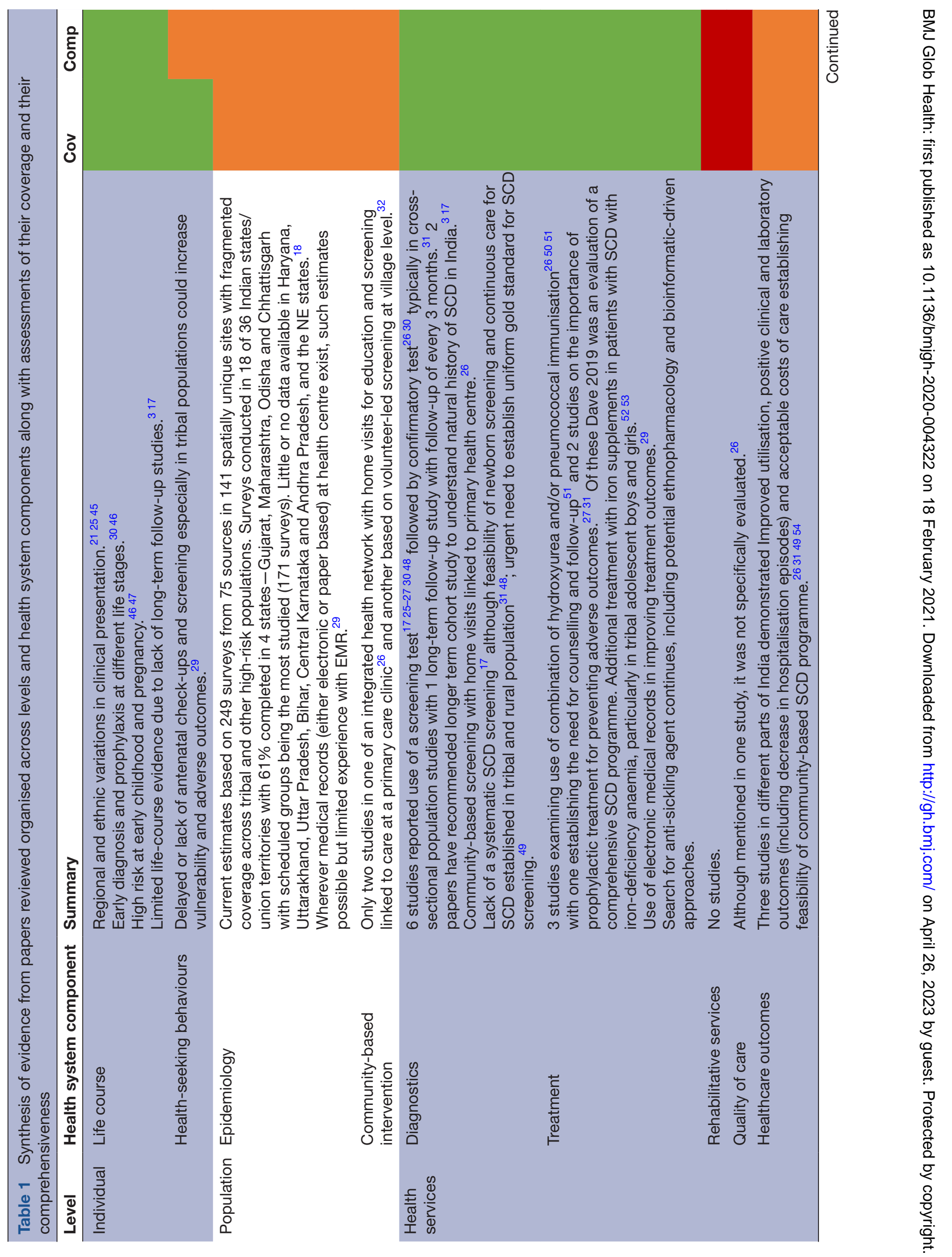




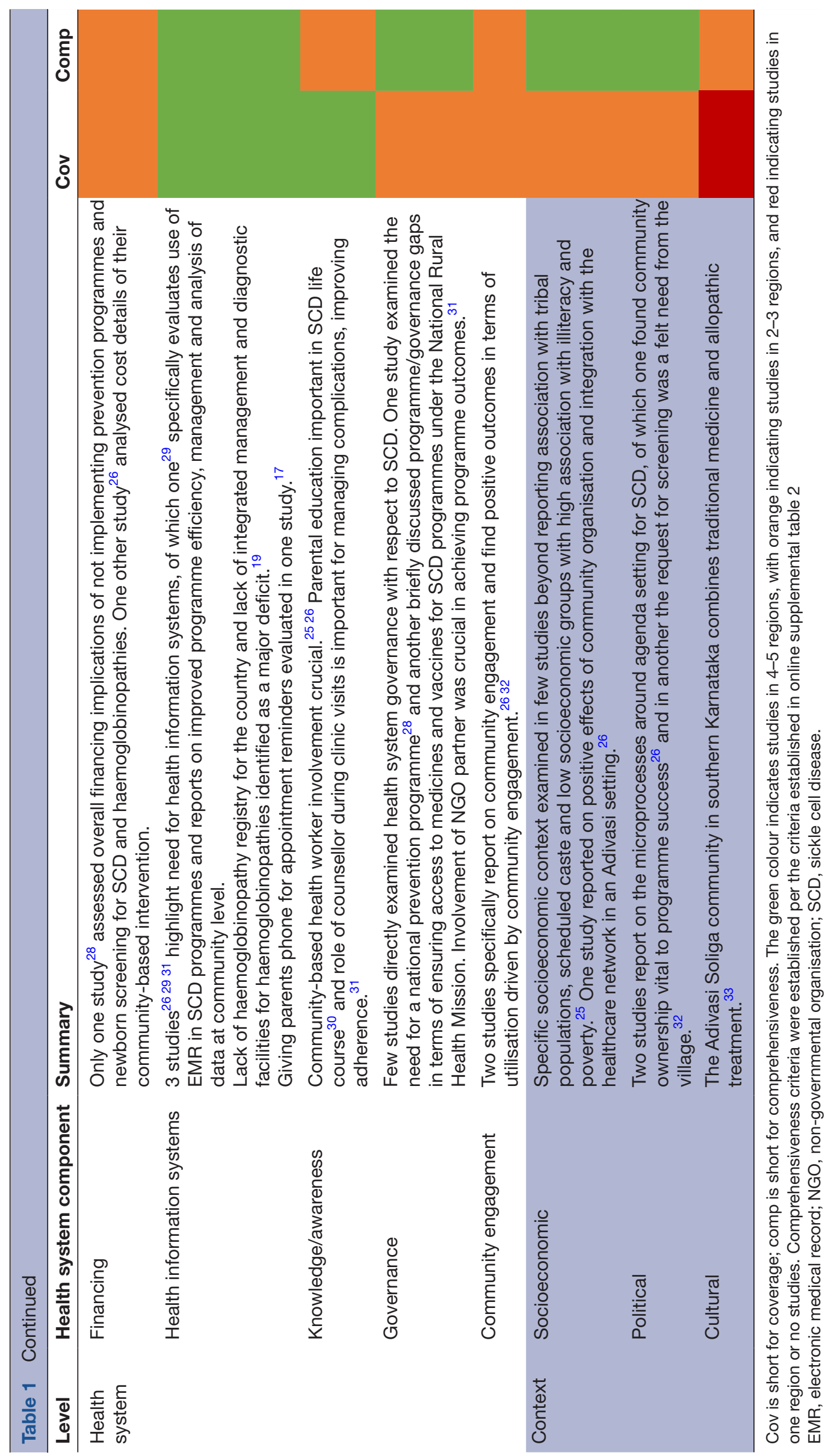


action research, for instance, were completely lacking with respect to SCD. Without adequate research and implementation sites that allow for this kind of participatory research and action with tribal communities, possible problems with respect to stigma and discrimination may not at all be problematised or investigated but may be important to keep in mind while designing programmes. See for instance the ethical difficulties of implementing population screening programmes that could identify SCD carriers which could fuel stigma and discrimination, ${ }^{22}$ or for instance the public health ethics of population screening and identifying disease without adequate health system preparedness to support them after. This is also a limitation of the analytical framework which relies on building blocks and does not include ethics, discrimination and power imbalances, all of which have contributed to tribal health inequities. ${ }^{22} 3940$

\section{Policy response}

The need for a policy response in the form of a formal policy document at the national level is an important first step, especially in LMICs. ${ }^{41}$ The current policy response to SCD in India is in the form of a draft policy for prevention and control of haemoglobinopathies (includes thalassemia, SCD and variant haemoglobin conditions) of the central government health ministry ${ }^{6}$ and the guidelines for prevention and control of haemoglobinopathies. ${ }^{42}$ One of the key proposals in the draft policy is to set up centres of excellence for haemoglobinopathies. The proposed centres however do not appear to explicitly focus on rehabilitative services and there is no mention of assessing or facilitating quality of care for patients with SCD. Expectedly, the documents focus on the important themes we identified for which there are studies (laboratory services, human resources, involvement of parent organisations and international collaborations) even if they do not specifically locate these policy options in the current evidence base. Various individual level measures are taken up including prenatal screening, newborn screening and clinical management of SCD. However, due to the lack of adequate geographical coverage of Indian studies, the policy too does not provide any adaptations to the multiple socioeconomic settings in India where affected communities live. Apart from acknowledging the inequities in the disease unfairly affecting economically and geographically disadvantaged communities, the policy response only addresses the curative and biomedical aspects of SCD, which could be a reflection of the lack of health policy and systems research focus and outputs on SCD. Furthermore, the engagement of SCD literature with axes of social inequalities in India including (but not limited to) caste, socioeconomic position, gender and other social vulnerabilities including disability and chronic mental illness is conspicuous by its absence, yet an important input in addressing health inequities in SCD. A recent commentary from the African context has called attention to the value of a social determinants lens in managing sickle cell disorders in sub-Saharan Africa to build a more holistic approach that would promote better health throughout the life course. ${ }^{16}$

In other LMICs (including some countries in Africa), the role of newborn screening, dedicated SCD-specific programmes that include engagement of parents in the care process, education and counselling, and other community-based interventions have been demonstrated to reduce morbidity and mortality. ${ }^{2}{ }^{43}$ Indeed, regional, national and global collaboration between universities, hospitals and governments across countries with high disease burden is an important step towards creating a systemic environment that could improve diffusion of practices and innovations across these settings. ${ }^{44}$

\section{CONCLUSION}

Despite availability of adequate evidence on the geospatial epidemiology of SCD, there are gaps in geographical coverage of the evidence across the country, as well as in comprehensiveness of the evidence across individual, population, services and systems levels. Current studies also do not critically engage with the overall health policy and systems environment within which patients with SCD experience their illness. Gaps in evidence at the health policy and systems level also limit solutions at that level and unfairly push the locus of action to individuals and communities. The review has identified key gaps that could inform the research agenda for action on SCD in India.

\section{Twitter Prashanth N Srinivas @prashanthns}

Acknowledgements The authors would like to thank Pragati Hebbar, Meena Putturaj and Deepa Bhat for their comments on the manuscript. They also thank several non-governmental organisations that have pioneered community-based care for various Adivasi communities in remote areas where government primary healthcare had not yet reached, particularly the pioneering work by Vivekananda Girijana Kalyana Kendra in BR Hills and the Gudalur Adivasi hospital in Nilgiris. VR thanks the Fulbright Nehru Student Research Program and US-India Educational Foundation for their support of this endeavour.

Contributors NSP and TS developed the conceptual framework. NSP and VR authored the introduction, analysis and conclusion sections. VR completed the systematic literature review, analysis table, supplemental tables and the methods section. SVJ assisted with literature review and analysis. TS helped with the analysis section. VR prepared the first draft and all authors reviewed the draft for submission.

Funding NSP received funding through DBT/Wellcome Trust India Alliance Intermediate Clinical and Public Health Research Fellowship (IA CPHI/16/1/502648) awarded to him. VR was supported by the Fulbright Nehru Student Research Program administered by the US-India Educational Foundation and the US Department of State, Bureau of Educational and Cultural Affairs.

Disclaimer The funders had no role in study design, data collection and analysis decision to publish or preparation of the manuscript.

Competing interests None declared.

Patient and public involvement statement This study is a desk review of existing literature and did not involve patients or any other respondents in the study. The review explored literature from individual to population-level evidence available through the stated method concerning sickle cell disease screening and management.

Patient consent for publication Not required.

Provenance and peer review Not commissioned; externally peer reviewed. 
Data availability statement All data relevant to the study are included in the article or uploaded as supplemental information. All data pertaining to the analysis are in the supplemental files 1-3.

Supplemental material This content has been supplied by the author(s). It has not been vetted by BMJ Publishing Group Limited (BMJ) and may not have been peer-reviewed. Any opinions or recommendations discussed are solely those of the author(s) and are not endorsed by BMJ. BMJ disclaims all liability and responsibility arising from any reliance placed on the content. Where the content includes any translated material, BMJ does not warrant the accuracy and reliability of the translations (including but not limited to local regulations, clinical guidelines, terminology, drug names and drug dosages), and is not responsible for any error and/or omissions arising from translation and adaptation or otherwise.

Open access This is an open access article distributed in accordance with the Creative Commons Attribution 4.0 Unported (CC BY 4.0) license, which permits others to copy, redistribute, remix, transform and build upon this work for any purpose, provided the original work is properly cited, a link to the licence is given, and indication of whether changes were made. See: https://creativecommons.org/ licenses/by/4.0/.

\section{ORCID iDs}

Tanya Seshadri http://orcid.org/0000-0002-7357-0472

Prashanth N Srinivas http://orcid.org/0000-0003-0968-0826

\section{REFERENCES}

1 Ware RE. Is sickle cell anemia a neglected tropical disease? PLOS Negl Trop Dis 2013;7:e2120.

2 Chakravorty S, Williams TN. Sickle cell disease: a neglected chronic disease of increasing global health importance. Arch Dis Child 2015;100:48-53.

3 Serjeant GR, Ghosh K, Patel J. Sickle cell disease in India: a perspective. Indian J Med Res 2016;143:21-4

4 Organization WH. The world health report 2000: health systems: improving performance. Geneva: World Health Organization, 2000.

5 Organization WH. Everybody's business: strengthening health systems to improve health outcomes: WHO's framework for action. Geneva: WHO, 2007.

6 InMinistry of Health and Family Welfare Gol. Draft policy for prevention and control of hemoglobinopathies - thalassemia, sickle cell disease and variant hemoglobins in India. In: Division NHM-BC, ed. New Delhi: Ministry of Health and Family Welfare Gol, 2018.

7 Saha N, Banerjee B. Haemoglobinopathies in the Indian subcontinent. A review of literature. Acta Genet Med Gemellol 1973;22:117-38.

8 Foy H, Brass W, Kondi A. Sickling and malaria. BMJ 1956;1:289-90.

9 Colah RB, Mukherjee MB, Martin S, et al. Sickle cell disease in tribal populations in India. Indian J Med Res 2015;141:509-15.

10 Sheikh K, George A, Gilson L. People-centred science: strengthening the practice of health policy and systems research. Health Res Policy Syst 2014;12:19.

11 Adam T, de Savigny D. Systems thinking for strengthening health systems in LMICs: need for a paradigm shift. Health Policy Plan 2012;27 Suppl 4:iv1-3.

12 Sheikh K, Ranson MK, Gilson L. Explorations on people centredness in health systems. Health Policy Plan 2014;29 Suppl 2:ii1-5.

13 Gilson L, Hanson K, Sheikh K, et al. Building the field of health policy and systems research: social science matters. PLOS Med 2011;8:e1001079.

14 Marchal B, Van Dormael M, Pirard M, et al. Neglected tropical disease (NTD) control in health systems: the interface between programmes and general health services. Acta Trop 2011;120 Suppl 1:S177-85.

15 Unger J-P, De Paepe P, Green A. A code of best practice for disease control programmes to avoid damaging health care services in developing countries. Int J Health Plann Manage 2003;18 Suppl 1:S27-39.

16 Berghs M, Ola B, Cronin De Chavez A, et al. Time to apply a social determinants of health lens to addressing sickle cell disorders in sub-Saharan Africa. BMJ Glob Health 2020;5:e002601.

17 Colah RB, Mehta P, Mukherjee MB. Newborn screening for sickle cell disease: Indian experience. Int J Neonatal Screen 2018;4:31.

18 Hockham C, Bhatt S, Colah R, et al. The spatial epidemiology of sickle-cell anaemia in India. Sci Rep 2018;8:17685.

19 Arksey H, O'Malley L. Scoping studies: towards a methodological framework. Int J Soc Res Methodol 2005;8:19-32.
20 Srinivas PN, Seshadri T, Velho N, et al. Towards health equity and transformative action on tribal health (theta) study to describe, explain and act on tribal health inequities in India: a health systems research study protocol. Wellcome Open Res 2019;4:202.

21 Ghosh K, Colah RB, Mukherjee MB. Haemoglobinopathies in tribal populations of India. Indian J Med Res 2015;141:505-8.

22 Ministry of Health \& Family Welfare, Ministry of Tribal Affairs, Government of India. Tribal health in India: bridging the gap and a roadmap for the future. Report of the expert Committee on tribal health, 2011. Available: http://tribalhealthreport.in/full-report/

23 Sudharshan H, Seshadri T. Chapter 2: Health of tribal people in Central India. In: Tribal Development Report (Vol 1 \& 2). Bharat Rural Livelihoods Foundation \& Routledge Publishers, 2020.

24 Olmen JV, Criel B, Bhojani U, et al. The health system dynamics framework: the introduction of an analytical model for health system analysis and its application to two case-studies. Health, Culture and Society 2012;2:1-21.

25 Colah R, Surve R, Nadkarni A, et al. Prenatal diagnosis of sickle syndromes in India: dilemmas in counselling. Prenat Diagn 2005;25:345-9.

26 Nimgaonkar V, Krishnamurti L, Prabhakar H, et al. Comprehensive integrated care for patients with sickle cell disease in a remote Aboriginal tribal population in southern India. Pediatr Blood Cancer 2014;61:702-5

27 Desai G, Dave K, Banerjee S, et al. Initial outcomes of a comprehensive care model for sickle cell disease among a tribal population in rural Western India. Int J Community Med Public Health 2016:1282-7.

28 Sinha S, Seth T, Colah RB, et al. Haemoglobinopathies in India: estimates of blood requirements and treatment costs for the decade 2017-2026. J Community Genet 2020;11:39-45.

29 Choubey M, Mishra H, Soni K, et al. Implementation of Indigenous electronic medical record system to facilitate care of sickle cell disease patients in Chhattisgarh. J Clin Diagn Res 2016;10:LC01-6.

30 Upadhye DS, Jain DL, Trivedi YL, et al. Neonatal screening and the clinical outcome in children with sickle cell disease in central India. PLoS One 2016;11:e0147081.

31 Dave K, Chinnakali P, Thekkur P, et al. Attrition from care and clinical outcomes in a cohort of sickle cell disease patients in a tribal area of Western India. Trop Med Infect Dis 2019;4. doi:10.3390/ tropicalmed4040125. [Epub ahead of print: 01 Oct 2019].

32 Patel J, Patel B, Gamit N, et al. Screening for the sickle cell gene in Gujarat, India: a village-based model. J Community Genet 2013;4:43-7.

33 Madegowda C, Rao CU. The sickle cell anemia health problems traditional and modern treatment practices among the Soliga tribes at BR.Hills, South India. Antrocom Online Journal of Anthropology 2013;9:243-51.

34 Payyappallimana U, Venkatasubramanian P. Exploring Ayurvedic knowledge on food and health for providing innovative solutions to contemporary healthcare. Front Public Health 2016;4:57.

35 Wang CJ, Kavanagh PL, Little AA, et al. Quality-Of-Care indicators for children with sickle cell disease. Pediatrics 2011;128:484-93.

36 Evensen CT, Treadwell MJ, Keller S, et al. Quality of care in sickle cell disease: cross-sectional study and development of a measure for adults reporting on ambulatory and emergency department care. Medicine 2016;95:e4528.

37 Seshadri T, Velho N, Narasimhamurti NS, et al. Examining tribal health inequalities around three forested sites in India: results of a cross-sectional survey. J Family Med Prim Care 2020;9:4788-96.

38 Colombatti R, Montanaro M, Guasti F, et al. Comprehensive care for sickle cell disease immigrant patients: a reproducible model achieving high adherence to minimum standards of care. Pediatr Blood Cancer 2012;59:1275-9.

39 Thresia CU, Srinivas PN, Mohindra KS, et al. The health of Indigenous populations in South Asia: a critical review in a critical time. Int J Health Serv 2020:20731420946588 (published Online First: 2020/08/14)

40 Gaitonde R, Ravindran TKS. Health inequities in India: a synthesis of recent evidence. 1st ED. Singapore: Springer, 2018: 1-239.

41 Piel FB, Hay SI, Gupta S, et al. Global burden of sickle cell anaemia in children under five, 2010-2050: modelling based on demographics, excess mortality, and interventions. PLoS Med 2013;10:e1001484

42 Ministry of Health \& Family Welfare, Government of India. Draft Policy for Prevention and Control of Hemoglobinopathies Thalassemia, Sickle Cell Disease \& Variant Hemoglobins in India, 2018. Available: https://www.nhp.gov.in/NHPfiles/1.pdf

43 Tluway F, Makani J. Sickle cell disease in Africa: an overview of the integrated approach to health, research, education and advocacy in Tanzania, 2004-2016. Br J Haematol 2017:177:919-29. 
44 Aygun B, Odame I. A global perspective on sickle cell disease. Pediatr Blood Cancer 2012;59:386-90.

45 Italia K, Jain D, Ghosh K, et al. Hydroxyurea in sickle cell disease-a study of clinico-pharmacological efficacy in the Indian haplotype. Blood Cells, Molecules, and Diseases 2009;42:25-31.

$46 \mathrm{Kar}$ BC, Devi S. Clinical profile of sickle cell disease in Orissa. Indian $J$ Pediatr 1997;64:73-7.

47 Desai G, Anand A, Shah P, et al. Sickle cell disease and pregnancy outcomes: a study of the community-based hospital in a tribal block of Gujarat, India. J Health Popul Nutr 2017;36:3

48 Italia Y, Krishnamurti L, Mehta V, et al. Feasibility of a newborn screening and follow-up programme for sickle cell disease among South Gujarat (India) tribal populations. J Med Screen 2015;22:1-7.

49 Saxena D, Yasobant S, Golechha M. Situational analysis of sickle cell disease in Gujarat, India. Indian J Community Med $2017 ; 42: 218-21$.
50 Power-Hays A, Ware RE. Effective use of hydroxyurea for sickle cell anemia in low-resource countries. Curr Opin Hematol 2020;27:172-80.

51 Deshpande SV, Bhatwadekar SS, Desai P, et al. Hydroxyurea in sickle cell disease: our experience in Western India. Indian J Hematol Blood Transfus 2016;32:215-20.

52 Mohanty D, Mukherjee MB, Colah RB, et al. Iron deficiency anaemia in sickle cell disorders in India. Indian J Med Res 2008;127:366-9.

53 Shah SP, Shah P, Desai S, et al. Effectiveness and feasibility of Weekly iron and folic acid supplementation to adolescent girls and boys through peer educators at community level in the tribal area of Gujarat. Indian J Community Med 2016;41:158-61.

54 Singh H, Dulhani N, Kumar BN, et al. Effective control of sickle cell disease with hydroxyurea therapy. Indian $\mathrm{J}$ Pharmacol 2010;42:32-5. 